\title{
-Mg primary phase formation and dendritic morphology transition in solidification of a Mg-Nd-Gd-Zn-Zr casting alloy
}

DOI:

10.1016/j.actamat.2016.06.035

\section{Document Version}

Accepted author manuscript

Link to publication record in Manchester Research Explorer

Citation for published version (APA):

Casari, D., Mirihanage, W., Falch, K. V., Ringdalen, I. G., Friis, J., Schmid-Fetzer, R., Zhao, D., Li, Y., Sillekens, W. H., \& Mathiesen, R. H. (2016). -Mg primary phase formation and dendritic morphology transition in solidification of a Mg-Nd-Gd-Zn-Zr casting alloy. Acta Materialia, 116, 177-187. https://doi.org/10.1016/j.actamat.2016.06.035

\section{Published in:}

Acta Materialia

\section{Citing this paper}

Please note that where the full-text provided on Manchester Research Explorer is the Author Accepted Manuscript or Proof version this may differ from the final Published version. If citing, it is advised that you check and use the publisher's definitive version.

\section{General rights}

Copyright and moral rights for the publications made accessible in the Research Explorer are retained by the authors and/or other copyright owners and it is a condition of accessing publications that users recognise and abide by the legal requirements associated with these rights.

\section{Takedown policy}

If you believe that this document breaches copyright please refer to the University of Manchester's Takedown Procedures [http://man.ac.uk/04Y6Bo] or contact uml.scholarlycommunications@manchester.ac.uk providing relevant details, so we can investigate your claim.

\section{OPEN ACCESS}




\section{$\alpha-M g$ primary phase formation and dendritic morphology transition in}

\section{solidification of a Mg-Nd-Gd-Zn-Zr casting alloy}

D. Casari ${ }^{\text {a, }}$, W.U. Mirihanage ${ }^{\mathrm{a}, 1}$, K. V. Falch ${ }^{\text {a }}$, I. G. Ringdalen ${ }^{\mathrm{b}}$, J. Friis ${ }^{\mathrm{b}}$, R. Schmid-Fetzer ${ }^{\text {c }}$, D. Zhao ${ }^{\text {d }}$, Y. Li $^{\text {d }}$, W. H. Sillekens ${ }^{\text {e }}$, R. H. Mathiesen ${ }^{\text {a }}$

a Department of Physics, Norwegian University of Science and Technology, Høgskoleringen 5, N-7491 Trondheim, Norway

b SINTEF Materials and Chemistry, N-7491 Richard Birkelands vei 2 B, Trondheim, Norway

c Institute of Metallurgy, Clausthal University of Technology, Robert-Koch-Straße 42, D-38678 ClausthalZellerfeld, Germany

d Department of Materials Science and Engineering, Norwegian University of Science and Technology, Alfred Getz vei 2 B, N-7491 Trondheim, Norway

e European Space Agency - ESTEC, Keplerlaan 1, 2201 AZ Noordwijk, The Netherlands

\section{ABSTRACT}

Microstructure evolution in the commercial Mg-Nd-Gd-Zn-Zr alloy Elektron 21, solidified under nearly isothermal conditions, has been studied via in-situ X-ray radiography. For cooling rates $i \leq 0.075 \mathrm{~K} / \mathrm{s}$, primary equiaxed $\alpha-\mathrm{Mg}$ dendrites undergo a morphological transition after nucleation and an initial stage of growth. The growth regime is observed to change abruptly from a 3D to a more pronounced anisotropic sheet-like growth occurring predominantly along $\langle 11 \overline{2} 0\rangle$ direction, with a $4-5$ times increase in the growth velocity. The experimental results together with thermodynamic calculations and density functional theory simulations give support to relate the morphology transition to the formation of ordered rare earth-zinc dimers in the $\{0001\}$ basal plane and $\{10 \overline{1} 1\}$ pyramidal plane of $\alpha-\mathrm{Mg}$ lattice. At the temperature where the morphological transition occurs, it is found that both the solute concentration and zinc diffusivity in $\alpha-\mathrm{Mg}$ are high enough for dimer formation to occur

* Corresponding Author at: Department of Physics, Norwegian University of Science and Technology, Høgskoleringen 5, Trondheim N-7491, Norway. Tel.: +47 73593368, e-mail address: daniele.casari@ntnu.no

1 Present address: School of Materials, The University of Manchester, Manchester M13 9PL, United Kingdom.

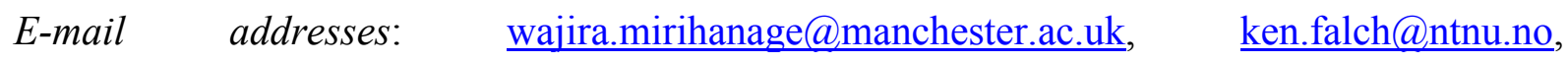
inga.g.ringdalen@sintef.no, $\quad$ jesper.friis@sintef.no, $\quad$ schmid-fetzer@tu-clausthal.de, dongdonz@ntnu.no, yanjun.li@ntnu.no, Wim.Sillekens@esa.int, ragnvald.mathiesen@ntnu.no. 
within a diffusive layer extending a few micrometres from the solid-liquid interface into $\alpha$ $\mathrm{Mg}$, and thereby open for increased solute-partitioning at the growth front.

\section{KEYWORDS}

Magnesium alloy; Rare earth; Solidification; X-ray radiography; Microstructure formation mechanism.

\section{INTRODUCTION}

In the pursuit of weight reduction and improved fuel efficiency in ground vehicles and aircrafts, magnesium alloys have received considerable attention among structural materials due to their low density and high specific strength and stiffness [1]. In addition to commonly used magnesium alloys containing $\mathrm{Al}$ and $\mathrm{Mn}(\mathrm{AM})$ or $\mathrm{Al}$ and $\mathrm{Zn}$ (AZ), new highperformance wrought and casting alloys containing rare earth (RE) elements such as $\mathrm{Nd}$ and Gd have been developed. Mg-RE alloys show improved mechanical properties compared to conventional AM and AZ alloys, as well as a significant age hardening response and good thermal stability up to $250{ }^{\circ} \mathrm{C}$ [2-9], making them suitable for more demanding engineering applications. Furthermore, addition of $\mathrm{Nd}$ is recognised as an effective approach to overcome the low ductility and mechanical anisotropy of wrought magnesium alloys at room temperature, thus improving their formability $[6,10]$.

Microstructures of AM, AZ and Mg-RE alloys have been characterised extensively by means of post-solidification metallographic investigations [11-20]. Aiming at predicting microstructure and properties of industrial magnesium casting alloys, recent attempts have been made to model the formation, growth orientations and morphologies of $3 \mathrm{D} \alpha-\mathrm{Mg}$ dendrites in a number of magnesium alloys [21-23]. It has been shown that $\alpha$-Mg dendrites grow with an almost perfect six-fold symmetry in the Mg-9 wt.\% Al alloy [21], with arms 
oriented along the $\langle 11 \overline{2} 0\rangle$ direction in the $\{0001\}$ basal plane. Phase-field simulations have also revealed both solid/liquid interface energy anisotropy and diffusivity as critical to the formation of dendrite morphologies. Regarding the solidification microstructure of the Mg- 40 wt.\% Zn alloy [22], a six-fold branched secondary dendritic structure has been observed to develop behind the tip of the $[11 \overline{2} 0]$ primary advancing trunk. Among these secondary arms, two follow $\langle 11 \overline{2} 0\rangle$ directions, whereas the remaining four branches are oriented along $\langle 22 \overline{4} 5\rangle$ directions. In their study on the 3D morphology of $\alpha-\mathrm{Mg}$ dendrites in Mg-30 wt.\% Sn and Mg-30 wt.\% Gd alloys [23], Yang and co-authors have reported the formation of eighteen-fold branched primary structures in both alloys, in which six arms lie in the $\{0001\}$ basal plane and grow along $\langle 11 \overline{2} 0\rangle$ direction, whereas the remaining twelve branches are located in a non-basal plane growing along the $\langle 11 \overline{2} 3\rangle$ direction. A further secondary branching along the same $\langle 11 \overline{2} 0\rangle$ and $\langle 11 \overline{2} 3\rangle$ directions develops from the primary trunks, leading to an intricate 3-D shape. The occurrence of such complex 3-D morphologies demonstrates that the growth of $\alpha-\mathrm{Mg}$ dendrites can be markedly influenced both by the type and the amount of solid solution elements. Nevertheless, apart from a very recent study by Wang et al. [24], dynamic phenomena or growth kinetics associated with the solidification microstructure evolution have not been addressed in detail.

In-situ X-ray radiography has emerged as a versatile technique in solidification science permitting real-time observations of microstructure spatiotemporal evolution through attenuation and/or phase shift of the X-ray field by the material. Apart from the wellestablished synchrotron-based investigations [25], recent advances in compact microfocus Xray source and high-efficiency detector technologies have allowed in-situ X-ray radiographic solidification experiments to be performed in home laboratories [26-29]. The home-lab technique provides image contrast exclusively by X-ray absorption, and accordingly its 
application is limited to systems in which the evolving phases can be distinguished from adequately sharp transitions in the X-ray attenuation across phase domains boundaries.

In the case of commercial magnesium foundry alloys, those belonging to the AM and AZ series will not generally provide appreciable solid-liquid absorption contrast at the X-ray photon energies required for sample transmission. Additional alloying by a contrast enhancing element, like the enhancement by $\mathrm{Cu}$-alloying successfully applied in studies of $\mathrm{Al}-\mathrm{Si}$ eutectics [30,31], should be sought for to open for studies in these systems. Some of the MgRE commercial variants, on the other hand, would be suitable for home laboratory in situ Xray radiographic studies without any additional alloying, as RE have appreciable photoelectric absorption cross sections at relevant X-ray photon energies [24]. The present manuscript reports on X-ray radiographic in-situ studies of $\alpha-\mathrm{Mg}$ primary microstructure formation and evolution in the commercial Mg-RE alloy Elektron 21.

\section{MATERIALS AND METHODS}

The deliberate alloying elements of Elektron 21 are $\mathrm{Nd} \sim 2.8 \mathrm{wt} . \%, \mathrm{Gd} \sim 1.5 \mathrm{wt} . \%, \mathrm{Zn} \sim 0.4$ wt.\%. $\mathrm{Zr}$ is usually added for grain refinement purposes at levels above its maximum solubility in molten $\mathrm{Mg}$ ( $\sim 0.4$ wt.\% for this multicomponent alloy). In the present work, several samples were machined from Elektron 21 cast ingots as delivered by Magnesium Elektron, and sectioned into $50 \times 5 \times 1 \mathrm{~mm}$ strips. The strips were manually ground with progressively finer grades of silicon carbide paper, up to 4000 grit, arriving at final sample dimensions of 50 x 5 x 0.16(1) $\mathrm{mm}(\mathrm{L} \mathrm{x} \mathrm{W} \mathrm{x} \mathrm{D).}$

A microfocus X-ray radiography setup, custom-built for in-situ solidification studies and described in detail elsewhere [26,27], was used for the experiments. The setup incorporated a new chamber to perform experiments under argon atmosphere with oxygen levels controlled $<0.5 \%$, preventing self-ignition of molten magnesium. In a compromise between X-ray 
absorption contrast and sample transmission, the X-ray source was operated at $55 \mathrm{keV}$ and 50 $\mu \mathrm{A}$.

The latest available version of the $\mathrm{Mg}$ database PanMg in the Pandat software [32] reports a liquidus temperature $T_{L} \sim 915.4 \mathrm{~K}$ for the alloy, with a solidification range of approximately $120 \mathrm{~K}$ (Figure 1). At $\mathrm{Zr}$ concentrations close to saturation, $\alpha-\mathrm{Mg}$ dendrites nucleate on the $\alpha$ $\mathrm{Zr}$ phase as a result of a peritectic transformation. Then, $\mathrm{Zr}$ dissolves completely in $\alpha-\mathrm{Mg}$ without producing additional phases. The Scheil module was used to simulate the solidification range; according to thermodynamic calculations, solidification of primary $\alpha-\mathrm{Mg}$ occurs over a wide range of $109 \mathrm{~K}$, whereas solidification of secondary phases $\mathrm{Mg}_{3} \mathrm{RE}$ and $\mathrm{Mg}_{41} \mathrm{RE}_{5}$, specifically $(\mathrm{Mg}, \mathrm{Zn})_{3}(\mathrm{Nd}, \mathrm{Gd})_{1}$ and $(\mathrm{Mg}, \mathrm{Zn})_{41} \mathrm{Nd}_{5}$, occurs only in the last $11 \mathrm{~K}$ of the solidification range.

\section{(Figure 1)}

In the solidification experiments, the furnace temperatures were set initially to $933 \mathrm{~K}$ and subsequently adjusted by fine tuning the heater elements until nearly isothermal conditions were reached and equiaxed nucleation was observed to occur close to the centre of the field of view (FoV). The setup allows experiments to be carried out with gravity parallel to the small thickness dimension (D) of the radiography sample cell. This dramatically limits both the buoyancy of primary phase crystals and thermosolutal convection in the melt. Four K-Type thermocouples positioned symmetrically about the FoV were employed to record the temperatures. Six different constant cooling rates, $i_{-}^{*}-\{0.0125,0.025,0.05,0.075,0.1,0.2$ $\mathrm{K} / \mathrm{s}$ \}, were applied during the solidification experiments and a number of three experiments were performed at each cooling rate. Microstructure evolution was recorded at a frame rate of 
$1 \mathrm{~Hz}$. The corresponding 12 bits per pixel greyscale images were subsequently post-processed by means of flat-fielding, noise filtering and edge sharpening techniques.

Some of the samples solidified at the two lowest $i$ were subjected to metallographic investigations. Areas including the FoV were extracted from the specimens and then carefully ground with $\mathrm{SiC}$ paper (4000 grit) followed by mechanical polishing employing 3 and $1 \mu \mathrm{m}$ diamond suspensions and a $0.04 \mu \mathrm{m}$ ethanol-based colloidal silica suspension. The postsolidification microstructure was examined in the $\mathrm{L} x \mathrm{~W}$ sample surface via back-scattered electrons (BSE) and electron back-scattered diffraction (EBSD) techniques using a ZEISS ULTRA 55 field emission scanning electron microscope equipped with a Nordif EBSD detector and TSL OIM software. The EBSD operating conditions were as follows: accelerating voltage $20 \mathrm{keV}$, sample tilt $70^{\circ}$, working distance $20 \mathrm{~mm}$ and scan steps $0.5-1$ $\mu \mathrm{m}$.

\section{RESULTS}

\subsection{X-ray Radiographic Experiments}

Figure 2a shows a series of images selected from a sequence with an Elektron 21 sample solidified at $i^{\circ}=0.0125 \mathrm{~K} / \mathrm{s}$. At the beginning of the sequence, $\alpha-\mathrm{Mg}$ dendrites with typical six-folded symmetry nucleate and grow in the centre of the FoV. The growth leads to solute enrichment in $\mathrm{Zn}$ and $\mathrm{RE}$ in the liquid surrounding the dendrites, which appears darker due to the increased X-ray absorption. Subsequently at $t=25 \mathrm{~s}$, a finer microstructure (marked "I") is observed to develop at much higher growth rate and with a distinctively different morphology than the original dendrites in the region. At $t=45 \mathrm{~s}$, a similar morphological feature is observed to develop directly from one of the six branches of an original dendrite ("II"), rapidly spreading in the liquid area in between previously formed dendrites. Two additional transition events ("III" and "IV") occur in the FoV at later stages. 


\section{(Figure 2)}

Instantaneous interface propagation velocities have been extracted throughout the full sequence for the regions I-IV where the morphological transition occurs, and are presented in Figure $2 b$. It is clear from this figure that an increase of the instantaneous interface propagation velocities by a factor $4-5$ can be associated with the transition. The subsidiary velocity peaks observed for regions I and II are attributed to side-branching/re-orientation of the evolving second morphologies. It should be noted that all the morphological transitions in the selected sequence and in the other sequences occur in regions with enhanced solute concentrations in the adjacent melt, typically in enclosed inter-dendritic regions.

As $i^{*}$ increases up to $0.075 \mathrm{~K} / \mathrm{s}$, finer $\alpha-\mathrm{Mg}$ dendrites are observed in the FoV. Nonetheless, the morphology transition can still be identified. At $\dot{i} \geq 0.1 \mathrm{~K} / \mathrm{s}$, the second morphology cannot be separated reliably from initial $\alpha-\mathrm{Mg}$ dendrites: its development is beyond the detection limit of the camera, both in terms of spatial and temporal resolutions (Figure 3).

\section{(Figure 3)}

The temperature difference, $\Delta T_{S M}=T_{\alpha-M g}-\bar{T}=T_{L}-\Delta T_{\kappa}-\bar{T}$, between the nucleation of $\alpha-\mathrm{Mg}$ dendrites and the observed initiation of the second morphology (SM) has been determined from a series of sequences collected with the same sample. Here $T_{\alpha-M g}$ is the primary phase nucleation temperature, $T_{L}$ the alloy liquidus temperature, $\Delta T_{\kappa}$ the curvature contribution to the nucleation undercooling as extracted for the envelopes of the first grains appearing in the FoV, while $\bar{T}$ is the average of the furnace temperatures recorded by the two thermocouples closest to the FoV [27]. Except for $i \geq 0.1 \mathrm{~K} / \mathrm{s}$, which do not yield a clearly detectable 
morphological transition, $\Delta T_{S M}$ values range approximately from 0.4 to $0.8 \mathrm{~K}$, where the curvature undercooling account for 0.1 to $0.125 \mathrm{~K}$.

\subsection{Post-Solidification Microstructure and EBSD Orientation Mapping}

Figure 4 shows an extract of the Elektron 21 alloy post-solidification microstructure processed at $i^{\circ}=0.0125 \mathrm{~K} / \mathrm{s}$. As reported previously [33], the as-cast microstructure consists of $\alpha-\mathrm{Mg}$ primary phase dendrites and an $\alpha-\mathrm{Mg}+\mathrm{Mg}_{3} \mathrm{RE}$ eutectic phase at grain boundaries. Owing to the specific furnace setting, the solidification started in the centre of the FoV (the red rectangle in Figure 4), with solidification fronts advancing symmetrically along the sample length direction. $i^{\circ}$ was kept at $0.0125 \mathrm{~K} / \mathrm{s}$ until the solidification occurred in the whole FoV. Subsequently, the sample was cooled at $\dot{i}^{\circ}>2 \mathrm{~K} / \mathrm{s}$. As a result, coarse $\alpha-\mathrm{Mg}$ dendrites and some shrinkage porosities are observed in the central region enclosing the FoV, whereas a finer microstructure is detected in the surrounding areas.

Figure 5 illustrates some selected radiograms from the experiment performed on the sample shown in Figure 4, together with the corresponding EBSD orientation map (the yellow rectangle in Figure 4). Several maps were taken and merged in order to include the FoV and contiguous areas. This granted a better view of both the crystallographic orientations of the initial $\alpha-\mathrm{Mg}$ dendrites and the preferential growth directions of the following second morphology.

\section{(Figure 4)}

\section{(Figure 5)}

At the beginning of the image sequence (Figure 5a), a couple of $\alpha$-Mg dendrites are observed to grow slowly. The morphological transition occurs at $t=30 \mathrm{~s}$ in the dendrite on the left (the scattered red dendrite in Figure 5b) and spreads rapidly in the liquid. Another growth event is 
noticed at $\mathrm{t}=150 \mathrm{~s}$ for a dendrite in the FoV centre (light blue dendrite, Figure $5 \mathrm{~b}$ ). At $\mathrm{t}=210$ $\mathrm{s}$, the $\alpha-\mathrm{Mg}$ primary phase occupies most of the FoV and no further growth is observed.

The EBSD orientation map (Figure 5b) indicates that the earliest nucleated $\alpha$-Mg dendrite on the left side of the FoV and the following finer structure developing from some of its primary branches have the same orientation, i.e. the (0001) basal plane nearly parallel to the $\mathrm{L} x \mathrm{~W}$ sample surface. A similar remark can also be made for the abovementioned light blue dendrite, and for the orange and cyan grains located on the right and lower middle sides of the EBSD orientation map, respectively.

Several L x W in-plane growth directions have been determined in a number of grains that were observed to undergo the morphology transition (Figure 5 and 6). For the sake of clarity, only some representative directions are shown in the BSE images (Figures 5c and $6 \mathrm{~b}$ ), and results are collected in Table 1. It should be noted that none of the post-solidified samples investigated by EBSD gave indication of growth twinning as a possible mechanism behind the increase in growth velocities associated with the morphological transition.

\section{(Figure 6)}

Table 1 - L x W in-plane growth directions of the second morphology for a number of selected grains shown in Figure 5 and 6.

\begin{tabular}{|c|c|c|}
\hline Grain & Measurement & L x W In-plane Growth Directions \\
\hline \multicolumn{3}{|c|}{ Figure 5} \\
\hline \multirow{7}{*}{ Red grain } & $\# 1$ & {$[\overline{2} 110]$} \\
\hline & $\# 2$ & {$[\overline{1} 2 \overline{1} 0]$} \\
\hline & \#3 & {$[1 \overline{2} 10]$} \\
\hline & \#4 & {$[11 \overline{2} 0]$} \\
\hline & \#5 & {$[\overline{1} 2 \overline{1} 0]$} \\
\hline & \#6 & [21̄10] \\
\hline & $\# 7$ & {$[11 \overline{2} 0]$} \\
\hline \multirow{3}{*}{ Light blue grain } & $\# 8$ & {$[2 \overline{1} \overline{1} 0]$} \\
\hline & $\# 9$ & {$[11 \overline{2} 2]$} \\
\hline & $\# 10$ & {$[4 \overline{3} \overline{1} 3]$} \\
\hline
\end{tabular}




\begin{tabular}{lll}
\hline & \multicolumn{3}{c}{ Figure 6} \\
\hline \multirow{3}{*}{ Pink grain } & $\# 1$ & {$[\overline{4} 401]$} \\
& $\# 2$ & {$[21 \overline{3} 2]$} \\
& $\# 3$ & {$[2 \overline{1} \overline{1} 1]$} \\
Green grain & $\# 4$ & {$[\overline{2} 201]$} \\
& $\# 5$ & {$[\overline{1} 100]$} \\
& $\# 6$ & {$[2 \overline{1} \overline{1} \overline{4}]$} \\
Purple grain & $\# 7$ & {$[\overline{1} \overline{2} 3 \overline{2}]$} \\
& $\# 9$ & {$[\overline{2} 3 \overline{1} 5]$} \\
\hline & $\# 10$ & {$[\overline{2} 110]$} \\
& $\# 11$ & {$[\overline{2} 4 \overline{2} 1]$} \\
& $\# 12$ & {$[\overline{4} 22 \overline{1}]$} \\
\hline
\end{tabular}

According to the pole distributions in Figures 5 and 6, development along $\langle 11 \overline{2} 0\rangle$ direction in the basal plane is the most frequent, whereas the $\langle 10 \overline{1} 0\rangle$ direction is less likely. Non-basal plane growth directions can also be extracted. As shown in the pole distributions of Figure 5e and $6 \mathrm{c}-\mathrm{e}$, some dendrites have at least one branch growing in $\langle 11 \overline{2} 3\rangle$. Contrary to previous studies [21-23,34], branching is also observed in the $\langle 0001\rangle$ direction (\#2 secondary arm of the pink grain in Figure 6a and corresponding pole distribution in Figure 6c). In this case, however, growth might be accentuated by the containment of the sample in the thickness direction, forcing the dendrite to develop along less favourable paths. It is clear, however, that a more detailed 3D investigation, like the one by Yang et al. [23], is required to have unambiguous information on all the actual 3D growth directions of $\alpha-\mathrm{Mg}$ dendrite branches.

\section{DISCUSSION}

From the X-ray radiograms, see e.g. Figure 2a, it can be seen that the second type morphology microstructure appears with a weaker image contrast than the original $\alpha$-Mg dendrites, which could be indicative of a marked change in the solid constitution. However, as growth proceeds, the second morphology gradually becomes indistinguishable from the original dendrites. It therefore seems reasonable to assume that the difference in X-ray absorption 
contrast between the first and the second morphology features relates to a marked change in solid thickness parallel to the image projection direction. Thus, the second type morphology appears as darker in the projected images due to substantially longer beam paths through the solute-enriched and attenuating liquid. This implies a transition in growth morphology from one more or less fully $3 \mathrm{D}$ volume spanning to a more anisotropic and pronounced sheet-like growth morphology.

According to the EBSD data, growth of second type morphology occurs predominantly along $\langle 11 \overline{2} 0\rangle$ crystallographic direction in the $\{0001\}$ basal plane (Figures 5 and 6 ). This is in agreement with the pyramid plane principle used by Pettersen et al. [34], the comparisons between reticular densities of the liquid and the solid in $\langle 10 \overline{1} 0\rangle$ and $\langle 11 \overline{2} 0\rangle$ directions made by Yang and co-authors using Chadwick's hard sphere model $[23,35]$ and the calculations of crystal-melt interfacial free energies performed by Sun et al. [36]. Although the second X-ray radiograph of Figure 2a may suggest otherwise (region I), the EBSD maps also demonstrate that the morphological transition does not involve new nucleation events, but rather a number of consecutive time-separated rapid spreads (Figure $2 b$ ) of initially finer microstructures into the $\mathrm{Zn}$ - and RE-enriched liquid in between already existing dendrites. It is not possible directly from radiography or from post-solidification microscopy to pin down the exact mechanism responsible for the morphological transition. Logically, it should involve a change at the atomic scale, either at the solid/liquid interface or alternatively in the bulk solid region adjacent to the interface, and the concurrent activation of preferential crystallographic directions whose fast development might be associated to an improved ability to accommodate solute atoms in the $\alpha-\mathrm{Mg}$ lattice.

Nie and co-authors demonstrated via statistical analysis of 3D atom probe data that cosegregations of $\mathrm{Gd}$ and $\mathrm{Zn}$ atoms in the form of $\mathrm{Gd}-\mathrm{Zn}$ dimers are likely to be present in the $\alpha-\mathrm{Mg}$ lattice in as-quenched $\mathrm{Mg}-1 \mathrm{Gd}-0.4 \mathrm{Zn}-0.2 \mathrm{Zr}$ (at.\%) samples even after prolonged 
solutionising up to $16 \mathrm{~h}$ at $500{ }^{\circ} \mathrm{C}$ [37]. Different from solute clusters, which typically contain more than a dozen solute atoms, dimers are much smaller atomic arrangements consisting of one or two pairs of Gd and $\mathrm{Zn}$ atoms that tend to segregate to each other in order to minimize the elastic strain that individual Gd or $\mathrm{Zn}$ substitutional atoms would produce in the $\alpha-\mathrm{Mg}$ lattice because of atomic radii differences $\left(\mathrm{r}_{\mathrm{Gd}}=0.180 \mathrm{~nm}, \mathrm{r}_{\mathrm{Zn}}=0.133 \mathrm{~nm}\right.$ and $\mathrm{r}_{\mathrm{Mg}}=0.160$ $\mathrm{nm})$. As reported in [37], these dimers are stable only at elevated temperatures and become gradually less detectable with increasing aging times at 200 and $250{ }^{\circ} \mathrm{C}$ due to the concomitant formation of $\gamma^{\prime \prime}$ and $\gamma^{\prime}$ precipitates.

In order to find support for such a co-segregation phenomenon to occur during solidification in the Elektron 21 alloy, solid solution concentrations (mass fractions) of the alloying elements $C_{S}(T), \mathrm{S}=\mathrm{Nd}, \mathrm{Gd}, \mathrm{Zn}$ have been calculated from the $\mathrm{Mg}$ database [32] for the formation of $\alpha-\mathrm{Mg}$ under Scheil conditions. To inspect and compare the relative changes in partitioning of the different elements both at the solid/liquid interface and in the solid phase, it was found convenient to look at differentials with respect to $T$ of the normalised concentrations, i.e. $\frac{1}{\bar{C}_{S}} \frac{d C_{S, s / l i n t}(T)}{d T}$ and $\frac{1}{\bar{C}_{S}} \frac{d C_{S, \text { solid }}(T)}{d T}$. Specifically, $C_{S}$ is the current average over the solute profile in the growing $\alpha-\mathrm{Mg}$, whereas $\bar{C}_{S}$ is the average value over the complete $\alpha-\mathrm{Mg}$ freezing range. The differentials are illustrated in Figure $7 \mathrm{a}$ and $7 \mathrm{~b}$ over the temperature interval associated with primary phase formation and morphological transition, and extended somewhat further into the $\alpha-\mathrm{Mg}$ solidification interval. As can be observed, $\frac{1}{\bar{C}_{N d}} \frac{d C_{N d, \text { solid }}(T)}{d T}, \frac{1}{\bar{C}_{G d}} \frac{d C_{G d, \text { solid }}(T)}{d T}$ and $\frac{1}{\bar{C}_{Z n}} \frac{d C_{Z n, \text { solid }}(T)}{d T}$ curves show a marked kink at about $\mathrm{T} \sim 915.3 \mathrm{~K}$, in reasonable proximity to overlap with the $\Delta T_{S M}$ estimates from the radiography sequences, whereas the solid/liquid interface curves remain smooth. This implies a marked increase in the ability to accommodate solute atoms in the $\alpha-\mathrm{Mg}$ lattice as solidification proceeds, which does not reflect any noticeable change in the solid 
concentration at the solid/liquid interface. Moreover, as the trends in the solid correlate for all the alloying elements, it is indeed possible that some sort of co-segregation takes place.

\section{(Figure 7)}

Density functional theory (DFT) simulations were carried out to investigate dimer formations similar to those reported by Nie et al. [37] as a possible mechanism to trigger the morphological transition. Several different dimer and double dimer constellations were investigated with the $\alpha-\mathrm{Mg}$ lattice expanded to values corresponding to $\mathrm{T}=915.3 \mathrm{~K}$, and with Gd and $\mathrm{Zn}$ substituting for $\mathrm{Mg}$ and arranged as nearest neighbours. Nd atoms were not included in the simulations. It is expected that $\mathrm{Nd}$ can substitute quite readily for $\mathrm{Gd}$ in the Gd-Zn dimers due to the small difference in atomic radii $\left(\mathrm{r}_{\mathrm{Nd}}=0.182 \mathrm{~nm}\right)$. Bulk calculations with dimers in a periodic bulk cell were performed using the Perdew-Burke-Ernzerhof (PBE) [38] exchange-correlation functional in framework of the Vienna Ab-initio Simulation Package (VASP) [39]. The simulations were relaxed using the conjugate gradient algorithm to a force convergence threshold of $0.005 \AA / \mathrm{eV}$, and an energy cutoff of $400 \mathrm{eV}$ was used. A supercell of $6 \times 4 \times 3 \mathrm{Mg}$ unit cells and a K-point grid fixed to $2 \times 2 \times 3$ were employed.

The results unequivocally point to Gd-Zn dimers as energetically favourable over a random solid solution (Figure 8). In fact, all the single and double dimer configurations tested gave a reduction in the system total energy. However, comparisons between the arrangements also reveal an evident anisotropy in energy reduction, implying a preferential formation of single and/or double dimers in a non-basal plane. This result is in good agreement with the activation of the $\langle 11 \overline{2} 0\rangle$ direction as the predominant growth orientation for the fastdeveloping second morphology. According to Bravais law the slowest growing directions of a crystal are the directions perpendicular to the closest packed planes. Thus, the growth of a 
dendrite trunk along a specific direction can be regarded as the growth of a pyramid whose axis is precisely that direction, and the closest packed planes are the pyramidal planes. As stated by Petterson et al. [34], $\{10 \overline{1} 1\}$ planes have to be such limiting closed packed planes in order to allow growth along $\langle 11 \overline{2} 0\rangle$. As Gd and $\mathrm{Zn}$ atoms form both single and double dimers by arranging in the $\alpha-\mathrm{Mg}$ lattice as nearest neighbours in order to reduce the system total energy (Figure 8), such atoms must necessarily arrange in consecutive $\{10 \overline{1} 1\}$ pyramidal planes at the shortest possible interplanar spacing $(\{10 \overline{1} 1\}$ planes are unevenly spaced). Therefore, since dimers are energetically favoured in both the $\{0001\}$ and the $\{10 \overline{1} 1\}$ planes, both compatible with growth along $\langle 11 \overline{2} 0\rangle$ direction, and since growth along directions perpendicular to these close packed planes is hindered, the anisotropic growth observed in Xray radiograms seems reasonable.

\section{(Figure 8)}

As can be also seen from the results, double dimers are energetically favourable over single dimers. Nevertheless, it should be noted that formation of single dimers will be considerably faster than a double dimer formation from a kinetic perspective: minimisation of the system total energy, in fact, would require the assembly of specific double dimer constellations consisting of alternate single dimers where Gd-Gd interatomic distance is longer than $\mathrm{Zn}-\mathrm{Zn}$ separation.

In order to relate a possible co-segregation and dimer formation to the observed morphological transition, a transport-based growth restriction at the solid-liquid interface must be established that incorporates dimer formation, takes into account the detected sheetlike growth anisotropy, and furthermore relates the transition to constitutional conditions at 
the interface and in the adjacent liquid at $\mathrm{T} \sim 915.3 \mathrm{~K}$. Recently, Das and co-workers $[40,41]$ have fitted anisotropic diffusivities for $\mathrm{Gd}$ and $\mathrm{Zn}$ in $\alpha-\mathrm{Mg}$ with experimental data from binary alloys measured up to $743 \mathrm{~K}$ and $603 \mathrm{~K}$, respectively. The models do not allow for a reliable anisotropic extension up to temperatures relevant for this study. In fact, the models indicate that the diffusive anisotropy should reduce with increasing temperatures [41]. It is important to note, however, that the isotropically averaged diffusion coefficient of $\mathrm{Zn}$ is larger than that of $\mathrm{Gd}$ in that range of temperature, becoming up to two orders of magnitude larger when the models are extended to $915.3 \mathrm{~K}$, i.e. $D_{Z n}^{\alpha-M g}(915.3 \mathrm{~K}) \sim 1.3 \cdot 10^{-12} \mathrm{~m}^{2} / \mathrm{s}$ and $D_{G d}^{\alpha-M g}(915.3 \mathrm{~K}) \sim 3.8 \cdot 10^{-14} \mathrm{~m}^{2} / \mathrm{s}$. In contrast, there is a lack of data regarding liquid diffusivities of $\mathrm{Zn}$ and Gd. However, diffusion coefficients can be predicted using the method proposed by Roy and Chhabra [42]. According to the authors, the diffusivity of a solute A in a solvent B accounting only for size effects can be calculated as:

$$
D_{\mathrm{AB}}=\frac{0.2 B R d_{\mathrm{B}}^{3}}{d_{\mathrm{A}}}\left[\frac{T}{V}\left(\frac{V-V_{0}}{V_{0}}\right)\right]_{\mathrm{B}}
$$

where $B$ and $V_{0}$ are two characteristic constants determined via the fluidity approach of Hildebrand [43], $V$ is the molar volume calculated as the ratio between the atomic weight of the solute element and its density at a temperature $T=T_{m}^{\text {pure } \mathrm{B}}$ [44], $R$ is the gas constant and $d_{\mathrm{A}, \mathrm{B}}$ are the Goldschmidt atomic diameters of solute and solvent. As shown in Table 2, calculated liquid diffusion coefficients are $D_{Z n}^{l} \sim 7.8 \cdot 10^{-9} \mathrm{~m}^{2} / \mathrm{s}$ and $D_{Z n}^{l} \sim 5.8 \cdot 10^{-9} \mathrm{~m}^{2} / \mathrm{s}$ at $\mathrm{T}=\mathrm{T}_{\mathrm{m}}^{\mathrm{Mg}}=923 \mathrm{~K}$, slightly higher than diffusivity data provided in [45]. Hence, at the diffusive time of $\sim 5 \mathrm{~s}$ set by interdendritic solute diffusion in the liquid to the average midpoint between neighbouring dendrites $\sim 200 \mu \mathrm{m}$, Zn may diffuse over lengths $\sim 6 \mu \mathrm{m}$ in $\alpha-\mathrm{Mg}$. From the equilibrium solid solution at $T=915.3 \mathrm{~K}$, the average distance between randomly solutionised Gd atoms is $\sim 1.5 \mathrm{~nm}$. Thus $\mathrm{Zn}$ is clearly capable to diffuse over 
distances far beyond the average Gd separation distance within the diffusive time set by transport in the liquid.

Table 2 - Prediction of $\mathrm{Nd}, \mathrm{Gd}$ and $\mathrm{Zn}$ diffusion coefficients in liquid $\mathrm{Mg}$. The molar volume $V_{0}$ is calculated at fluidity $\varphi=0$ through the fluidity approach of Hildebrand [43], whereas $V$ is calculated as the ratio between the atomic weight of the solute element $\left(A_{r}\right)$ and its density at $\mathrm{T}=\mathrm{T}_{\mathrm{m}}^{\mathrm{Mg}}$. The characteristic constant $B$ is obtained by the equation $\varphi\left(T_{m}\right)=\frac{1}{\eta\left(T_{m}\right)}=$ $B\left(\frac{V-V_{0}}{V_{0}}\right)$ [43] from viscosity data [46,47]. Liquid diffusion coefficients are determined from equation (1). References of data available in literature are in square brackets.

\begin{tabular}{|c|c|c|c|c|c|c|c|c|c|}
\hline \multirow[t]{2}{*}{$\begin{array}{l}\text { Elem } \\
\text { ent }\end{array}$} & \multirow{2}{*}{$\begin{array}{c}\text { Melting } \\
\text { Temperat } \\
\text { ure } \\
\mathbf{T}_{\mathbf{m}}(\mathbf{K})\end{array}$} & \multirow{2}{*}{$\begin{array}{c}\text { Density at } \\
T=T_{m} \\
\underset{\left(\mathrm{kg} / \mathrm{m}^{3}\right)}{\rho_{\mathrm{m}}}\end{array}$} & \multirow{2}{*}{$\begin{array}{l}\text { Density at } \\
T=T_{m}^{M g} \\
\rho\left(\mathrm{kg} / \mathrm{m}^{3}\right)\end{array}$} & \multirow{2}{*}{$\begin{array}{l}\text { Atomic } \\
\text { Weight } \\
\begin{array}{c}\text { Ar }_{\mathrm{r}}\left(\mathbf{x} 10^{-3}\right. \\
\mathrm{kg} / \mathrm{mol})\end{array}\end{array}$} & \multicolumn{2}{|c|}{ Molar Volume } & \multirow{2}{*}{$\begin{array}{c}\text { Characte } \\
\text { ristic } \\
\text { constant }\end{array}$} & \multirow{2}{*}{$\begin{array}{c}\text { Goldsch } \\
\text { midt } \\
\text { Atomic } \\
\text { Diamet } \\
\text { er } \\
\text { d }\left(\mathbf{x ~ 1 0} \mathbf{1 0}^{-}\right. \\
10 \mathrm{~m})\end{array}$} & \multirow{2}{*}{$\begin{array}{c}\text { Predicted } \\
\text { Liquid } \\
\text { Diffusivit } \\
\text { ies } \\
D^{l}\left(\mathbf{x} 10^{-9}\right. \\
\left.\text { m }^{2} / \mathbf{s}\right)\end{array}$} \\
\hline & & & & & $\begin{array}{l}V_{0}\left(\begin{array}{ll}\left(x 0^{-6}\right. \\
\left.\mathbf{m}^{3} / \mathbf{m o l}\right)\end{array}\right. \\
\end{array}$ & $\begin{array}{l}V\left(x 1^{-6}\right. \\
\left.\mathbf{m}^{3} / \mathbf{m o l}\right)\end{array}$ & & & \\
\hline Mg & $923[48]$ & $1584[48]$ & 1584 & 24.3 [49] & $13.0[43]$ & 15.3 & $3500[43]$ & 3.20 & - \\
\hline Nd & $1289[48]$ & 6585 [46] & $6742^{*}$ & $144.2[49]$ & 20.9 & 21.4 & 8861 & 2.66 & 5.69 \\
\hline Gd & 1587 [48] & 7410 [47] & $7662^{\dagger}$ & 157.3 [49] & 19.1 & 20.5 & 2715 & 3.60 & 5.75 \\
\hline Zn & 693 [48] & $6570[48]$ & $6349^{*}$ & 65.4 [49] & $9.5[43]$ & 10.3 & $5700[43]$ & 3.64 & 7.79 \\
\hline
\end{tabular}

* a linear relationship between density at room temperature $\left(7010 \mathrm{~kg} / \mathrm{m}^{3}\right)$ and density at $T=T_{m}^{N d}$ was used.

${ }^{\dagger}$ a linear relationship between density at room temperature $\left(7900 \mathrm{~kg} / \mathrm{m}^{3}\right)$ and density at $T=T_{m}^{G d}$ was used.

* calculated as $\rho(T)=\rho_{m}-k \cdot\left(T_{m}^{M g}-T_{m}^{Z n}\right), k=0.959$ [48].

The suggested scenario is therefore as follows. After $\alpha-\mathrm{Mg}$ nucleation and initial transient growth, the growth of the primary crystals follows pretty close to equilibrium at the rate set by the isothermal cooling. At a critical point however, the interdendritic liquid concentration in $\mathrm{Zn}$ has risen to a level where the interatomic separation distance of RE elements in solid solution, as well as the solid solution level and the diffusive transport of $\mathrm{Zn}$ in $\alpha-\mathrm{Mg}$ reach critical values where a non-negligible amount of dimers form both in the $\{0001\}$ basal plane and in the $\{10 \overline{1} 1\}$ pyramidal plane in the bulk region adjacent to the growth front. The formation of dimers evacuates some of the solid solution and leave increased capacity for partitioning of additional solute elements at the growth front, thus enhancing attachment and growth along $\langle 11 \overline{2} 0\rangle$ direction in a self-sustaining mechanism. The limited number of grains 
and grain orientations available, the actual orientation relationships between neighbouring grains, and quite likely also the sample confinement hinder growth along $\langle 11 \overline{2} 0\rangle$ in all cases, leaving grains to subsequently expand by growth along directions with higher activation energies (e.g. $\langle 11 \overline{2} 3\rangle$, also reported in [23]).

Two further aspects should also be kept in mind: (i) the interface propagation velocities increase by a factor 4-5 during the morphological transition (Figure 2b), thus reducing $\mathrm{Zn}$ diffusion length in $\alpha-\mathrm{Mg}$ by the same factor to $\sim 1.2 \mu \mathrm{m}$; (ii) Gd concentration in $\alpha-\mathrm{Mg}$ is approximately four times higher than $\mathrm{Zn}$ at $\mathrm{T}=915.3 \mathrm{~K}(0.04$ at.\% Gd vs. 0.01 at.\% $\mathrm{Zn})$, so that at maximum only $25 \%$ of the Gd atoms could possibly co-segregate. As a result, average separation distance between Gd-Zn dimers becomes $\sim 2.5 \mathrm{~nm}$ if all $\mathrm{Zn}$ atoms would engage in dimers. However, as this distance is about 3 orders of magnitude less than the corrected $\mathrm{Zn}$ diffusion length, dimer formation probably occurs only at a small fraction of the available sites during the morphological transition. Finally, it should be stressed that no attempts have been made to distinguish between $\mathrm{Nd}-\mathrm{Zn}$ or $\mathrm{Gd}-\mathrm{Zn}$ as possible dimer constellations. In the simulation and discussion it is referred to Gd simply because the Scheil simulation predicts Gd concentration at $\mathrm{T}=915.3 \mathrm{~K}$ to account for $\sim 80 \%$ of the $\mathrm{RE}$ in the $\alpha-\mathrm{Mg}$ solid solution.

To further substantiate the current hypothesis of co-segregation and RE-Zn dimer formation, a series of radiography experiments were carried out with samples prepared from a Mg-Nd-GdZr alloy with Elektron21-like constitution, but without any Zn. Applying the same set of parameters, and from repeated series of experiments, only steady $3 \mathrm{D}$ equiaxed dendritic growth was observed without detecting any subsequent morphological transitions at any cooling rates. Thus, it seems evident that Zn plays a pivotal role in the occurrence of the morphological transition. 


\section{CONCLUSIONS}

The work reported presents the first in-situ observations of $\alpha-\mathrm{Mg}$ primary phase formation and evolution in the commercial Mg-Nd-Gd-Zn-Zr casting alloy Elektron 21. A morphological transition involving some of the original equiaxed dendrites has been detected at cooling rates $i \leq 0.075 \mathrm{~K} / \mathrm{s}$. The variation from a volume spanning $3 \mathrm{D}$ to a more pronounced anisotropic-type growth at temperatures close to $T_{L}$ has been attributed to the formation in bulk regions adjacent to the solidification front of ordered RE-Zn atomic arrangements energetically favourable over a random solid solution. In accordance with EBSD measurements, the adjustment of the $\alpha-\mathrm{Mg}$ lattice to this new lower energetic state enhances the growth most prominently along $\langle 11 \overline{2} 0\rangle$ direction.

\section{ACKNOWLEDGEMENTS}

The authors wish to acknowledge financial support from the ExoMet project, which is cofounded by the European Commission in the $7^{\text {th }}$ Framework Programme (contract FP7NMP3-LA-2012-280421), by the European Space Agency and by the individual partner organisations. Authors also gratefully acknowledge Prof. Lars Arnberg (NTNU) and Dr. Ehsan Ghassemali (Jönköping University) for fruitful discussions.

\section{REFERENCES}

[1] A.A. Luo, Magnesium casting technology for structural applications, Journal of Magnesium and Alloys 1 (2013) 2-22.

[2] P. Lyon, I. Syed, S. Heaney, Elektron 21 - An Aerospace Magnesium Alloy for Sand Cast and Investment Cast Applications, Adv. Eng. Mater. 9 (2007) 793-798. 
[3] T. Mohri, M. Mabuchi, N. Saito, M. Nakamura, Microstructure and mechanical properties of a Mg-4Y-3RE alloy processed by thermo-mechanical treatment, Mater. Sci. Eng. A 257 (1998) 287-294.

[4] B.L. Mordike, Creep-resistant magnesium alloys, Mater. Sci. Eng. A 324 (2002) 103112.

[5] S.M. Zhu, M.A. Gibson, J.F. Nie, M.A. Easton, G.L. Dunlop, Primary Creep of DieCast Magnesium-Rare Earth based alloys, Metall. Mater. Trans. A 40 (2009) 20362041.

[6] J. Bohlen, S. Yi, D. Letzig, K.U. Kainer, Effect of rare earth elements on the microstructure and texture development in magnesium-manganese alloys during extrusion, Mater. Sci. Eng. A 527 (2010) 7092-7098.

[7] D. Wu, R.S. Chen, W. Ke, Microstructure and mechanical properties of a sand-cast Mg-Nd-Zn alloy, Mater. Design 58 (2014) 324-331.

[8] T. Honma, T. Ohkubo, K. Hono, S. Kamado, Chemistry of nanoscale precipitates in $\mathrm{Mg}-2.1 \mathrm{Gd}-0.6 \mathrm{Y}-0.2 \mathrm{Zr}$ (at.\%) alloy investigated by the atom probe technique, Mater. Sci. Eng. A 395 (2005) 301-306.

[9] J. Li, W. Jie, G. Yang, Effect of gadolinium on aged hardening behavior, microstructure and mechanical properties of $\mathrm{Mg}-\mathrm{Nd}-\mathrm{Zn}-\mathrm{Zr}$ alloy, Trans. Nonferrous Met. Soc. China 18 (2008) 27-32.

[10] K. Hantzsche, J. Bohlen, J. Wendt, K.U. Kainer, S.B. Yi, D. Letzig, Effect of rare earth additions on microstructure and texture development of magnesium alloy sheets, Scripta Mater. 63 (2010) 725-730.

[11] A.K. Dahle, Y.C. Lee, M.D. Nave, P.L. Schaffer, D.H. StJohn, Development of the ascast microstructure in magnesium aluminium alloys, Journal of Light Metals 1 (2001) $61-72$ 
[12] K. Hirai, H. Somekawa, Y. Takigawa, K. Higashi, Effects of Ca and Sr addition on mechanical properties of a cast AZ91 magnesium alloy at room and elevated temperature, Mater. Sci. Eng. A 403 (2005) 276-280.

[13] Y. Guangyin, S. Yangshan, D. Wenjiang, Effect of bismuth and antimony additions on the microstructure and mechanical properties of AZ91 magnesium alloy, Mater. Sci. Eng. A 308 (2001) 38-44.

[14] A. Kiełbus, T. Rzychoń, R. Cibis, Microstructure of AM50 die casting magnesium alloy, JAMME 18 (2006) 135-138.

[15] A. Luo, M.O. Pekguleryuz, Cast magnesium alloys for elevated temperature applications, J. Mater. Sci. 29 (1994) 5259-5271.

[16] T. Rzychoń, A. Kiełbus, Microstructure of WE43 casting magnesium alloy, JAMME $21(2007) 31-34$.

[17] J. Li, R. Chen, Y. Ma, W. Ke, Hot Tearing of Sand Cast Mg-5 wt.\% Y-4 wt.\% RE (WE54) alloy, Acta Metall. Sin. 26 (2013) 728-734.

[18] J. M. Kim, J.S. Park, Microstructure and tensile properties of Mg-Zn-Gd casting alloys, Int. J. Cast Metal. Res. 24 (2011) 127-130.

[19] J. Li, R. Chen, W. Ke, Microstructure and mechanical properties of Mg-Gd-Y-Zr alloy cast by metal mould and lost foam casting, Trans. Nonferrous Met. Soc. China 21 (2011) 761-766.

[20] A. Kiełbus, Microstructure and mechanical properties of Elektron 21 alloy after heat treatment, JAMME 20 (2007) 127-130.

[21] M.Y. Wang, J.J. Williams, L. Jiang, F. De Carlo, T. Jing, N. Chawla, Dendritic morphology of $\alpha-\mathrm{Mg}$ during the solidification of $\mathrm{Mg}$-based alloys: 3D experimental characterization by X-ray synchrotron tomography and phase-field simulations, Scripta Mater. 65 (2011) 855-858. 
[22] M.Y. Wang, Y.J. Xu, T. Jing, G.Y. Peng, Y.N. Fu, N. Chawla, Growth orientations and morphologies of $\alpha-\mathrm{Mg}$ dendrites in Mg-Zn alloys, Scripta Mater. 67 (2012) 629632.

[23] M. Yang, S.-M. Xiong, Z. Guo, Characterisation of the 3-D dendrite morphology of magnesium alloys using synchrotron X-ray tomography and 3-D phase-field modelling, Acta Mater. 92 (2015) 8-17.

[24] Y. Wang, L. Peng, Y. Li, X. Cheng, N. Wang, Y. Zhao, Y. Fu, L.-Q. Chen, W. Ding, The effect of low cooling rates on dendrite morphology during directional solidification in Mg-Gd alloys: In situ X-ray radiographic observation, Mater. Lett. 163 (2016) 218-221.

[25] R.H. Mathiesen, L. Arnberg, H. Nguyen-Thi, B. Billia, In Situ X-Ray Video Microscopy as a Tool in Solidification Science, JOM 64 (2012) 76-82.

[26] C. Rakete, C. Baumbach, A. Goldschmidt, D. Samberg, C.G. Schroer, F. Breede, C. Stenzel, G. Zimmermann, C. Pickmann, Y. Houltz, C. Lockowandt, O. Svenonius, P. Wiklund, R.H. Mathiesen, Compact x-ray microradiograph for in situ imaging of solidification processes: Bringing in situ x-ray micro-imaging from the synchrotron to the laboratory, Rev. Sci. Instrum. 82 (2011) 105-108

[27] A. G. Murphy, D. J. Browne, W. U. Mirihanage, R. H. Mathiesen, Combined in situ X-ray radiographic observations and post-solidification metallographic characterisation of eutectic transformations in $\mathrm{Al}-\mathrm{Cu}$ alloy systems, Acta Mater. 61 (2013) 4559-4571.

[28] H. Nguyen-Thi, G. Reinhart, G. Salloum Abou Jaoude, R.H. Mathiesen, G. Zimmermann, Y. Houltz, D. Voss, A. Verga, D.J. Browne, A.G. Murphy, XRMONGF: A novel facility for solidification of metallic alloys with in situ and time-resolved 
X-ray radiographic characterization in microgravity conditions, J. Cryst. Growth 374 (2013) 23-30.

[29] A.G. Murphy, W.U. Mirihanage, D.J. Browne, R.H. Mathiesen, Equiaxed dendritic solidification and grain refiner potency characterised through in situ X-radiography, Acta Mater. 95 (2015) 83-89.

[30] R.H. Mathiesen, L. Arnberg, Y. Li, V. Meier, P.L. Schaffer, I. Snigireva, A. Snigirev, A.K. Dahle, X-Ray Videomicroscopy Studies of Eutectic Al-Si Solidification in Al-SiCu, Metall. Mater. Trans. A 42 (2011) 170-180.

[31] A. Darlapudi, M. Felberbaum, R.H. Mathiesen, A.K. Dahle, The Influence of Cu on Eutectic Nucleation and Morphology in Hypoeutectic Al-Si Alloys, in: H. Weiland, A. D. Rollett and W.A. Cassada (Eds.), ICAA13: $13^{\text {th }}$ International Conference on Aluminum Alloys, John Wiley \& Sons, Hoboken, NJ, USA, 2012, pp. 1475-1482.

[32] Pandat Software and PanMg database, Release Date: 2016, CompuTherm LLC, Madison, WI, USA, http://www.computherm.com.

[33] A. Kiełbus, T. Rzychoń, L. Lityńska-Dobrzyńska, G. Dercz, Characterization of $\beta$ and $\mathrm{Mg}_{41} \mathrm{Nd}_{5}$ equilibrium phases in Elektron 21 magnesium alloy after long-term annealing, Solid State Phenom. 163 (2010) 106-109.

[34] K. Pettersen, O. Lohne, N. Ryum, Dendritic solidification of magnesium alloy AZ91, Metall. Mater. Trans. A 21 (1990) 221-230.

[35] H. Fredriksson, U. Akerlind, Solidification and Crystallization Processing in Metals and Alloys, first ed., John Wiley \& Sons, Hoboken, 2012.

[36] D.Y. Sun, M.I. Mendelev, C.A. Becker, K. Kudin, T. Haxhimali, M. Asta, J.J. Hoyt, A. Karma, D.J. Srolovitz, Crystal-melt interfacial free energies in hep metals: a molecular dynamics study of Mg, Phys. Rev. B 73 (2006) 1-12. 
[37] J.F. Nie, K. Oh-ishi, X. Gao, K. Hono, Solute segregation and precipitation in a creepresistant Mg-Gd-Zn alloy, Acta Mater. 56 (2008) 6061-6076.

[38] J.P. Perdew, K. Burke, M. Ernzerhof, Generalized Gradient Approximation Made Simple, Phys. Rev. Lett. 77 (1996) 3865-3868.

[39] G. Kresse, J. Furthmüller, Efficiency of ab-initio total energy calculations for metals and semiconductors using plane-wave basis set, Comp. Mater. Sci. 6 (1996) 15-50.

[40] S.K. Das, Y.M. Kim, T.K. Ha, I.H. Jung, Investigation of anisotropic diffusion behavior of $\mathrm{Zn}$ in hcp $\mathrm{Mg}$ and interdiffusion coefficients of intermediate phases in the Mg-Zn system, Calphad 42 (2013) 51-58.

[41] S.K. Das, Y.M. Kim, T.K. Ha, I.H. Jung, Thermodynamic modeling and diffusion kinetic experiments of binary Mg-Gd and Mg-Y systems, Acta Mater. 71 (2014) 164175.

[42] A.K. Roy, R.P. Chhabra, Prediction of Solute Diffusion Coefficients in Liquid Metals, Metall. Mater. Trans. A 19 (1988) 273-279.

[43] J.H. Hildebrand, Viscosity and Diffusivity: A Predictive Treatment, first ed. WileyInterscience, New York, 1977.

[44] A.F. Crawley, Densities of Liquid Metals and Alloys, Int. Mater. Rev. 19 (1974) 3248.

[45] S. Liu, G. Yang, W. Jie, Selection of the solidification path of Mg-Zn-Gd ternary casting alloy, Acta. Metall. Sin. 51 (2015) 580-586 (in Chinese).

[46] P.-F. Paradis, T. Ishikawa, N. Koike, Y. Watanabe, Study of Molten Lanthanum, Praseodymium, and Neodymium by Electrostatic Levitation, JSMAJ 25 (2008) 407412. 
[47] T. Ishikawa, J.T. Okada, P.-F. Paradis, Y. Watanabe, Thermophysical Property Measurements of Liquid Gadolinium by Containerless Methods, Int. J. Thermophys. $31(2010) 388-398$.

[48] C.R. Hammond, Properties of the Elements and Inorganic Compounds, in: W.M. Haynes, D.R. Lide, T.J. Bruno (Eds.), CRC Handbook of Chemistry and Physics $96^{\text {th }}$ Edition, Taylor \& Francis Group, Boca Raton, 2015, pp. 128-131.

[49] Mathematica 10.0 (ElementData function), Release Date: July 2014, Wolfram Research, Inc., Long Hanborough, Oxfordshire OX29 8FD, UK, http://www.wolfram.com.

\section{FIGURE CAPTIONS}

Figure 1 - Equilibrium phase fractions for the Elektron 21 alloy.

Figure 2 - (a) Images taken from a sequence of X-ray radiograms showing the time evolution of the $\alpha-\mathrm{Mg}$ primary phase in the Elektron 21 alloy under nearly isothermal conditions at $i^{\circ}=$ $0.0125 \mathrm{~K} / \mathrm{s}$. The initial $\alpha-\mathrm{Mg}$ dendrites appear as bright, while the secondary morphologies are distinctively darker. The grey levels in the liquid phase relate to its constitution, where enhanced solute concentration gives darker image pixels. The regions marked with I, II, III and IV represent the spatial locations where a morphologically different structure appeared. (b) Instantaneous interface velocities extracted for the dendrites that undergo the transition in regions I-IV. 
Figure 3 - X-ray radiograms of the evolving Elektron 21 alloy solidification microstructure at $\dot{i}=0.1 \mathrm{~K} / \mathrm{s}$. A fine-size equiaxed dendritic structure is predominant. Original dendrites and second morphologies are difficult to distinguish.

Figure 4 - BSE micrograph of the post-solidification microstructure of a sample solidified at $\dot{i}=0.0125 \mathrm{~K} / \mathrm{s}$. The image represents the $\mathrm{L} \times \mathrm{W}$ sample surface, with $\mathrm{L}$ in the vertical direction. The as-cast microstructure consists of $\alpha-\mathrm{Mg}$ primary phase dendrites (dark grey) and an $\alpha-\mathrm{Mg}+\mathrm{Mg}_{3} \mathrm{RE}$ eutectic phase at grain boundaries (white). Shrinkage porosities are also detected. The red rectangle highlights the FoV as observed during the X-ray radiographic experiment, whereas the yellow rectangle denotes the area that underwent EBSD investigation. For further details, see Figure 5.

Figure 5 - (a) X-ray radiograms displaying the solidification of the sample shown in Figure 3. Notice the prominent second morphology developing from the leftmost dendrite. (b) EBSD orientation map of the area marked by the yellow rectangle in Figure 3. A number of growth directions of the second morphology are depicted in (b) and in the corresponding BSE micrograph (c) for the red and light blue dendrites. (d) and (e) Pole distributions with respect to the $\langle 11 \overline{2} 0\rangle$ and $\langle 11 \overline{2} 3\rangle$ growth directions for the red and light blue dendrites, respectively. Red dendrite: all growth orientations (\#1 to \#7) belong to the $\langle 11 \overline{2} 0\rangle$ set of directions. Light blue dendrite: $\# 8$ belongs to $\langle 11 \overline{2} 0\rangle$, whereas $\# 9$ and $\# 10$ to $\langle 11 \overline{2} 3\rangle$. Despite no direct evidence from the solidification sequence, it is likely that the orange and azure grains also underwent morphology transitions.

Figure 6 - (a) EBSD orientation map of another Elektron 21 sample solidified at $i^{\circ}=0.0125$ $\mathrm{K} / \mathrm{s}$. A number of growth directions of the second morphology are depicted in (a) and in the 
corresponding BSE micrograph (b) for the pink, green and purple dendrites. (c), (d) and (e) Pole distributions with respect to the $\langle 0001\rangle,\langle 10 \overline{1} 0\rangle,\langle 11 \overline{2} 0\rangle$ and $\langle 11 \overline{2} 3\rangle$ growth directions for the pink, green and purple dendrites, respectively. Pink dendrite: \#1 growth orientation belongs to $\langle 10 \overline{1} 0\rangle$ set of directions, $\# 2$ to $\langle 0001\rangle$, \#3 to $\langle 11 \overline{2} 0\rangle$ and $\# 4$ to $\langle 11 \overline{2} 3\rangle$. Green dendrite: $\# 5$ and $\# 8$ belong to $\langle 10 \overline{1} 0\rangle$, \#6 to $\langle 11 \overline{2} 0\rangle$ and $\# 7$ to $\langle 11 \overline{2} 3\rangle$. Purple dendrite: $\# 9$ and $\# 12$ belong to $\langle 11 \overline{2} 0\rangle$, whereas $\# 10$ and $\# 11$ to $\langle 11 \overline{2} 3\rangle$.

Figure 7 - Calculated first derivatives of the normalised concentrations of $\mathrm{RE}$ and $\mathrm{Zn}$ alloying elements (a) at the solid/liquid interface and (b) in the solid phase.

Figure 8 - Examples of bulk model configurations investigated through DFT simulations. $\Delta \mathrm{E}_{915.3}$ represents the difference in system total energy for the different dimer configurations compared to the reference configuration, with the $\alpha-\mathrm{Mg}$ lattice constants expanded to $\mathrm{T}=$ 915.3 K values. $\mathrm{Mg}$ atoms are marked in blue, $\mathrm{Gd}$ in red and $\mathrm{Zn}$ in yellow. 